\title{
DIAGNÓSTICO DE PRÁTICAS DE REDUÇÃO DOS IMPACTOS AMBIENTAIS NO ENTORNO ADOTADAS POR OBRAS RESIDENCIAIS DE DIFERENTES REGIÕES DA CIDADE DE SÃO PAULO (SP)
}

\author{
João Alexandre PASCHOALIN FILHO ${ }^{1}$; Paulo Roberto Lima BEZERRA ${ }^{2}$, Ana Cristina de FARIA ${ }^{3}$, Larissa Regina \\ Gonçalves Jacintho de OLIVEIRA ${ }^{4}$ \\ 1,2,3,4 Universidade Nove de Julho - Programa de Mestrado em Gestão Ambiental e Sustentabilidade, Programa \\ de Mestrado em Cidades Inteligentes e Sustentáveis. \\ paschoalinfilho@yahoo.com
}

Submetido 24/11/2016 - Aceito 11/07/2017

DOI: $10.15628 /$ holos.2017.5383

\section{RESUMO}

A Construção Civil consiste em importante agente de desenvolvimento do país. Contudo, responde por significativos impactos ambientais decorrentes de suas atividades. Dentre os impactos causados pelas obras, destacam-se àqueles que ocorrem durante a etapa executiva dos edifícios, principalmente na região do entorno destes, tais como: poluição sonora, contaminação do solo, sujeira de vias, poeira, entupimento de sistemas de drenagem de águas pluviais etc. Dentro deste contexto, esta pesquisa objetiva determinar se construtoras localizadas na cidade de São Paulo adotam, em suas obras, ações de sustentabilidade, de forma a mitigar impactos decorrentes de suas atividades e cumprir legislações ambientais. A metodologia empregada foi o estudo de casos múltiplos em nove obras, com abordagem exploratória e análise quantitativa. Para tal, foi elaborado um checklist com itens baseados em recomendações de sistemas de certificação Green Building (LEED, Processo ACQUA e Selo Casa Azul). A ferramenta de pesquisa foi submetida à avaliação de juízes e, posteriormente, utilizada em visitas realizadas nas obras. Por meio da análise dos dados pode-se constatar que nem todas as construtoras possuíam preocupação com ações de mitigação de impacto de suas obras na vizinhança onde estas se encontravam.

PALAVRAS-CHAVE: Construção Civil, Green Building, Impacto ambiental, Sustentabilidade.

\section{DIAGNOSTIC OF PRACTICES FOR ENVIRONMENT IMPACT REDUCTION ADOPTED BY RESIDENTIAL CONSTRUCTION WORKS IN DIFFERENT REGIONS OF THE CITY OF SAO PAULO / SP}

\section{ABSTRACT}

The civil construction consists in an important national development agent. However, this economic sector is responsible for significant environmental impacts due its activities. Among the impacts of civil works, can highlight those that occur during the executive stage of buildings, mainly in the surrounding such area, such as noise pollution, soil contamination, dust, obstruction of pluvial drainage systems etc. Due this situation, this research aims to determine if constructions located in the city of São Paulo adopted in their works, sustainability actions to mitigate impacts of its activities and comply with environmental legislation. The methodology used was the multiple cases studies in nine construction works, approach with exploratory and quantitative analysis. To this end, was developed a checklist with items based on certification systems with recommendations Green Building (LEED, ACQUA process and Blue House Seal). The checklist was subjected to evaluation of judges and subsequently used in visits in the construction works. Through the analysis of data could be seen that not all builders had concern with impact mitigation actions of his works in the neighborhood where they situed.

KEYWORDS: Civil Construction, Environmental Impact, Green Building, Sustainability. 


\section{INTRODUÇÃO}

A Construção Civil configura-se como um importante setor da economia brasileira, uma vez que seu crescimento traz consigo toda uma cadeia de empresas ligadas a produção de insumos e serviços essenciais para abastecê-la (Paschoalin, Storopoli, Dias \& Duarte, 2015). Dessa forma, é certo afirmar que este setor consiste no termômetro da economia nacional, pois consiste naquele que mais prontamente responde a situações favoráveis e o que primeiro apresenta retração em períodos de estagnação.

A inserção da variável ambiental nas construções consiste em uma condição essencial para o alcance do desenvolvimento sustentável de uma sociedade. Dessa forma, é necessário preocupar-se com a sustentabilidade em todas as etapas do ciclo de vida de um edifício, desde sua concepção, projeto, construção, manutenção, até sua demolição ou retrofit, considerando sempre o conceito de Triple Bottom Line, tal como apresentado por Elkington (1997).

No Brasil, a dificuldade em preservar o meio ambiente é agravada pelos grandes desafios que o setor da construção enfrenta cotidianamente em termos de déficit habitacional e infraestrutura, tanto para transporte, comunicação, abastecimento de água, saneamento, energia, atividades comerciais e industriais (Bomfati \& Silva, 2004). Tal fato, aliado a filosofias de projeto conservadoras e técnicas construtivas ultrapassadas, estimulam o consumo excessivo de matéria-prima natural, o aumento da geração de resíduos sólidos e poluentes decorrentes dos processos construtivos; impactando tanto o meio ambiente natural quanto o urbano.

Segundo Arif, Bendi e Toma-Sabbagh (2012), estima-se que cerca de $40 \%$ dos resíduos sólidos produzidos mundialmente advém de atividades ligadas à Construção Civil. Morais (2006) apresenta dados relativos a algumas cidades brasileiras de médio e grande porte, nas quais a massa de Resíduos de Construção Civil (RCC), percentualmente, varia entre $41 \%$ a $70 \%$ da massa total de Resíduos Sólidos Urbanos (RSU).

Dentro deste contexto, a certificação ambiental das obras consiste em um importante instrumento na implementação de práticas sustentáveis no setor. Dessa forma, esta pesquisa objetiva verificar se construtoras localizadas na cidade de São Paulo adotam, em suas obras, ações de sustentabilidade, de forma a mitigar impactos decorrentes de suas atividades e cumprir legislações ambientais. Portanto, este trabalho será norteado de forma a responder a seguinte questão de pesquisa: "Quais os procedimentos das construtoras estudadas na adoção de ações de redução dos impactos causados por suas obras na região do entorno?".

Para se responder esta questão, foi realizado um estudo de casos múltiplos em nove construções residenciais de alto padrão, em que se verificou a conformidade destas obras em relação à implantação de ações de sustentabilidade por meio de um checklist elaborado pelos pesquisadores. Os itens componentes desta ferramenta foram baseados em legislações ambientais específicas e diretrizes de sistemas de certificação Green Building (LEED, Processo ACQUA e Selo Casa Azul). 


\section{REVISÃO BIBLIOGRÁFICA}

A Construção Civil está no topo das atividades industriais que mais causam impactos ambientais. Entre estes, Paschoalin Filho e Graudenz (2012) destacam: fim de reservas naturais não renováveis do material explorado, alteração na paisagem, desmatamento, erosão, poluição do ar decorrente de emissão de gás carbônico na atmosfera e poluição sonora. Além dos impactos gerados durante a extração das matérias-primas naturais, também ocorrerão os impactos causados nas etapas posteriores, ou seja, na construção, demolição, manutenção, adequação e reforma dos edifícios.

De acordo com Oliveira (2002), mesmo que tardiamente conscientizado, o setor da Construção Civil tem agido decisivamente para que suas atividades agridam menos à natureza. Entre os impactos causados, Paschoalin Filho e Graudenz (2012) destacam: fim de reservas naturais não renováveis do material explorado, alteração na paisagem, desmatamento, erosão, poluição do ar decorrente de emissão de gás carbônico na atmosfera e poluição sonora. Além dos impactos gerados durante a extração das matérias-primas naturais, também ocorrerão os impactos causados nas etapas posteriores, ou seja, na construção, demolição, manutenção, adequação e reforma dos edifícios.

Para Achillas et al. (2011), os RCC gerados causam grande preocupação por consistirem em cerca de $60 \%$ de toda massa de RSU produzida diariamente no Brasil. Segundo Achillas et al. (2011), esta situação incorre em muitas dificuldades no descarte dos RCC. Os autores salientam que, quando despejados em locais impróprios, tais como: florestas, córregos, barrancos ou em terrenos vazios, estes causam a degradação do local, erosão, contaminação de solo, poços, lençóis freáticos e águas de superfície.

Conforme Lima (2009), é importante que a concepção do projeto arquitetônico já tome decisões que levem à redução dos impactos e as interferências da obra no entorno. Outra atitude que deve ser levada em conta em fase inicial é o aperfeiçoamento do detalhamento do projeto, pois reduzirá as perdas por detalhamentos inexatos, da mesma forma que a compra desses materiais, quando feita de forma dispendiosa (Lima, 2009).

Motta (2009) considera que a preocupação ambiental no setor da Construção Civil é essencial na redução do impacto ambiental das obras, cabendo às empresas do setor a adoção de práticas de gerenciamento e fiscalização baseadas em conceitos coerentes com a sustentabilidade.

Neste contexto, a certificação ambiental consiste em uma ferramenta que permite às empresas estabelecerem um processo contínuo de gerenciamento de seus impactos sobre o meio ambiente, podendo ter resultados efetivos na melhoria do desempenho ambiental das empresas; além de constituir-se em valioso instrumento para consolidação da corresponsabilidade envolvendo as empresas e os órgãos de controle ambiental.

De acordo com a ABNT NBR ISO: 14004/2005, à medida que aumentam as preocupações com a qualidade do meio ambiente, as organizações têm voltando sua atenção para os impactos ambientais causados por suas atividades, produtos e serviços. O desempenho ambiental de uma organização tem importância para seus stakeholders, incluindo o público consumidor. Atingir um sólido desempenho ambiental requer um comprometimento organizacional com uma abordagem sistemática e com a melhoria contínua de Sistemas de Gestão Ambiental (SGA). 
De acordo com Casado (2012), em termos mundiais, a Construção Civil no decorrer de suas atividades cotidianas responde pelo consumo de $21 \%$ da água tratada, $42 \%$ da energia elétrica, pelo lançamento de $25 \%$ das emissões de $\mathrm{CO}_{2}$ e $65 \%$ da geração de resíduos sólidos. No entanto, o autor ressalta que construir seguindo orientações e critérios de sistemas de certificação ambiental traz diversos benefícios ambientais, tais como: o consumo de energia é, em média, 30\% menor; o consumo de água sofre redução de $30 \%$ a $50 \%$; a redução da emissão de $\mathrm{CO}_{2}$ pode alcançar $30 \%$ e a redução na geração de resíduos poderá variar entre $50 \%$ a $90 \%$, conforme dados do GBCB (Green Building Council Brasil), organização responsável pela certificação.

O primeiro sistema de avaliação ambiental de construções foi lançado em 1990, na Inglaterra. Este sistema chama-se BREEAM, ou Building Research Estabilishment Enviromental Assessment Method. A partir de então, diversas literaturas foram publicadas e outros sistemas foram criados. No ano de 1999 foi criado o americano LEED (Leadership in Energy and Enviromental Design); em 2002 o francês HQE (Haute Qualité Enviromentable) e o japonês CasBee (Comprehensive Assessment System for Building Enviromental Efficiency). Apenas no ano de 2007 chegou ao Brasil o sistema americano para certificação de "construções verdes", a partir da criação do GBCB (Green Building Council Brazil) e, em 2008, surgiu o primeiro selo brasileiro, denominado Processo AQUA (Alta Qualidade Ambiental), elaborado pela Fundação Vanzolini e baseado no sistema francês HQE (Motta, 2009).

Casado (2012) comenta que, para empreendimentos que desejam adquirir a certificação LEED existem diversos pré-requisitos, ligados não somente à gestão de resíduos. É necessário, também estar atento ao tipo de terreno, sua localização e o entorno, consumo de água, qualidade do ar dentro da edificação, eficiência do uso de energia. Estas medidas garantem que ocorra preservação do meio ambiente antes, durante e após a conclusão da obra.

Coelho (2010) salienta a necessidade de se elaborar um projeto sustentável, o qual não se resume apenas em planejamento econômico e racionalização do uso de água e energia elétrica. $\mathrm{Na}$ visão do autor, a sustentabilidade possui um aspecto muito mais amplo e inclui preocupações com a continuidade da empresa investidora e, principalmente, o bem-estar do morador, do usuário e da comunidade do entorno do empreendimento.

Na visão de Grunberg, Medeiros e Tavares (2014), os selos ambientais são de grande importância na melhoria da qualidade dos ambientes construídos, bem como na redução impactos causados pelas obras ao meio ambiente. Os autores, após compararem três sistemas de certificação Green Building (LEED, ACQUA e SACEF), por meio da metodologia de análise hierárquica, identificaram que os sistemas Selo Casa Azul e Processo ACQUA apresentaram melhor performance, uma vez que foram desenvolvidos (SACEF) e adaptados (ACQUA) para as especificidades nacionais. Mas, de acordo com o GBC-Brasil (Green Building Council) (2012), o Brasil se mantém na 4a posição no ranking de empreendimentos com certificação LEED, somente atrás dos Estados Unidos, China e Emirados Árabes Unidos.

De acordo com Alcino (2008), além dos diversos sistemas de certificação ambiental existentes há, inclusive, normas regulamentadoras a fim de estabelecer certificação ambiental, tanto no âmbito da construção civil e resíduos provenientes de suas atividades, quanto da gestão ambiental como um todo. Dentre normas, sistemas e métodos nacionais e internacionais, destacam-se alguns dos mais utilizados no Brasil, segundo Alcino (2008): 
- ABNT NBR ISO 14.001: Consiste em uma norma, pertencente à ISO 14.000, que é um conjunto de normas internacionais desenvolvidas pela Internacional Organization for Standardization (ISO). Esta norma especifica requisitos relativos a um Sistema de Gestão Ambiental, orientando as organizações a estabelecerem e avaliarem a eficácia dos procedimentos destinados a definir políticas e objetivos ambientais, atingir a conformidade com eles e demonstrá-los a terceiros. A ISO 14001 define os componentes de um Sistema de Gestão Ambiental (SGA) e especifica critérios para implementação e aprimoramento, assim como apresenta orientações sobre como as organizações devem aplicar, melhorar e realizar a manutenção de um SGA.O SGA tem como um de seus principais objetivos, capacitar uma organização a atender a seus objetivos ambientais, assegurar o cumprimento das exigências nacionais e/ou internacionais (ABNT, 2005). A fim de padronizar o SGA da empresa, a ISO 14.001 estabelece requisitos básicos, cuja organização deve apresentar para obter certificação, tais como: política ambiental, aspectos e impactos ambientais, objetivos e metas, planejamento, análises críticas, entre outros (ABNT, 2005)

- PBQP-H (Programa Brasileiro da Qualidade e Produtividade do Habitat): Configura-se como um programa do Governo Federal para cumprimento dos compromissos firmados pelo Brasil quando da assinatura da Carta de Istambul na Conferência do Habitat II/1996 (PBPQ-H, 2009). O principal objetivo do Programa é garantir à organização do setor da Construção Civil em torno de dois fatores: i) a melhoria da qualidade do habitat; e ii) a modernização da produção. Para promover estas melhorias e modernizações, foi estabelecida uma série de ações, entre as quais se destacam: avaliação da conformidade de empresas de serviços e obras, melhoria da qualidade de materiais, formação e requalificação de mão de obra, normalização técnica, avaliação de tecnologias inovadoras, informação ao consumidor e promoção da comunicação entre os setores envolvidos. Linhares, Ferreira e Ritter (2007) comentam que diversas construtoras brasileiras possuem certificações ISO 9001 e PBQP-H. Segundo os autores, as construtoras vêm se organizando qualitativamente, visando estas certificações, de forma que possam obter financiamento de suas obras junto às instituições bancárias públicas e privadas. Afonso, Ribeiro, Souza e Cunha (2014) destacam que, ambas as certificações, são prérequisitos para as empresas construtoras aprovarem seus projetos junto à Caixa Econômica Federal (CEF), a fim de participarem do Programa Minha Casa Minha Vida (MCMV).

- LEED (Leadership in Energy and Environmental Design): Criado pelo U.S. Green Building Council (GBC), o LEED é um sistema de certificação e orientação ambiental de edificações de uso geral; sendo, atualmente, o selo de qualidade ambiental (selo verde) mais utilizado em todo o mundo, inclusive no Brasil (Casado, 2012). Para receber o selo verde, a construção deve atender alguns pré-requisitos que são obrigatórios e garantem um desempenho mínimo necessário a este empreendimento. Além disso, deve respeitar a vários outros critérios que valem pontos e, conforme o atendimento mínimo da pontuação possível, a empresa obtém o selo nível básico, que ainda pode ser prata, ouro ou platina, dependendo do desempenho da construção, que deverá levar estes critérios 
em consideração desde a escolha do local do empreendimento, desenvolvimento do projeto e construção em si.

- Processo AQUA (Alta Qualidade Ambiental): Este é um processo de gestão total de projetos de Construção Civil, a fim de obter Alta Qualidade Ambiental em empreendimentos de construção no Brasil. A certificação e a marca "Processo AQUA" são concedidas pela Fundação Vanzolini, com base em auditorias presenciais independentes. Este processo é o primeiro selo que levou em conta as especificidades do Brasil para elaborar seus critérios, que avaliam a gestão ambiental das obras e as especificidades técnicas e arquitetônicas. O referencial técnico dessa marca é uma adaptação da certificação francesa Démarche HQE (Fundação Vanzolini, 2010).

Segundo a Fundação Vanzolini (2010), a implementação de dois elementos fundamentais, citados a seguir, devem ser apresentados pelo empreendimento interessado em adquirir o selo:

i) Sistema de Gestão do Empreendimento (SGE): define a qualidade ambiental desejada e a sua aplicação para o edifício, assim como permite gerenciar o conjunto dos processos operacionais relacionados às fases de programa, concepção e realização da construção (Fundação Vanzolini, 2010); e ii) Qualidade Ambiental do Edifício (QAE): estrutura-se em quatorze categorias (conjuntos de preocupações) subdivididas em diversos itens, desde a criação de um canteiro de obras com baixo impacto ambiental até a gestão dos resíduos e o conforto acústico interno da edificação, por exemplo; sempre visando a gerenciar os impactos sobre o ambiente exterior como um todo e promover um espaço interior sadio e confortável.

Para tanto, é importante que, além das medidas, seja efetuado um registro e monitoramento do consumo, com comunicação constante dos valores e as metas a serem alcançadas. $O$ registro dos consumos ajuda a criar uma base de dados sobre o consumo da obra, que pode ser utilizada futuramente para a definição de metas de consumo (Fundação Vanzolini, 2010). Dessa maneira, observa-se que há diversos tipos de certificações utilizadas na Construção Civil, que preconizam a redução dos impactos ambientais. Na sequência, serão abordados os aspectos metodológicos da pesquisa.

\section{METODOLOGIA}

\subsection{Caracterização da pesquisa}

De acordo com Yin (2010), o estudo de caso consiste em uma investigação empírica, uma metodologia que abrange planejamento, técnicas de coleta de dados e análise dos mesmos. Para Miguel (2007), trata-se de uma análise aprofundada de um, ou mais objetos, de forma a permitir seu amplo conhecimento. Para o autor, o objetivo do estudo de caso consiste em aprofundar o conhecimento acerca de algo ou um problema, o qual ainda não se encontra completamente conhecido. Segundo Godoy (1995), o estudo de caso é uma estratégia de pesquisa bem aceita pelos pesquisadores, uma vez que possibilita determinar as causas de alguns fenômenos que poderão somente ser analisados dentro do contexto da vida real. Os estudos de casos podem ser classificados, de acordo com Yin (2010), em exploratório, explanatório ou descritivo, ou seja, em função de seu conteúdo e objetivo final; ou em relação a quantidade de casos estudados (caso único ou múltiplos). Ainda de acordo com o autor, o estudo de caso poderá se utilizar de seis 
fontes potenciais de informação, sendo estas: documentos, registros, entrevistas, observação direta, observação dos participantes e artefatos físicos.

Dessa forma, pode-se considerar esta pesquisa como um estudo de casos múltiplos e de caráter exploratório, em que os pesquisadores estudaram, ao todo, nove obras de edifícios residenciais localizadas na cidade de São Paulo (SP). De acordo com Godoy (1995), quando o estudo de caso envolve dois ou mais sujeitos, este pode ser considerado como sendo de casos múltiplos.

Em relação à forma de análise dos dados, pode-se caracterizar esta pesquisa como sendo de caráter quantitativo, uma vez que foram utilizadas análises estatísticas descritivas para compreender e explicar, de maneira mais adequada, os fenômenos observados pelos pesquisadores. Na visão de Godoy (1995), ainda que os estudos de caso sejam, em sua essência, qualitativos, estes poderão comportar dados quantitativos, de forma a explicar alguma questão investigada. A autora ressalta que, quando o estudo de caso vem municiado de uma análise quantitativa, geralmente o tratamento estatístico não é sofisticado.

\subsection{Elaboração da ferramenta de pesquisa - checklist}

Como ferramenta de pesquisa, foi utilizado um checklist elaborado pelos pesquisadores, no intuito de detectar nas obras, ações de redução dos impactos ambientais no entorno dos canteiros. A elaboração dos itens componentes do checklist foi baseada nas principais diretrizes ambientais de programas de certificação verde Green Building, tais como: LEED, Processo ACQUA e Selo Casa Azul da Caixa Econômica Federal, bem como em procedimentos observados nos sistemas de certificação de qualidade de obras ISO 9.001 e PBQP-H.

Após a construção da ferramenta de pesquisa, esta foi apresentada para dois consultores ambientais, especialistas em sistemas de certificação Green Building, de forma que estes pudessem opinar e sugerir a inclusão ou remoção de itens. Dessa forma, foi possível validar o checklist como uma ferramenta de pesquisa apta a mensurar as conformidades das ações em relação à redução dos impactos das obras em suas vizinhanças. Alexandre e Coluci (2011) recomendam sempre submeter um instrumento de pesquisa, após sua elaboração, à avaliação de juízes, ou seja, pessoas de experiência e capacidade comprovadas na área em estudos, para que estas possam avaliar e validar as assertivas. O Quadro 1 apresenta o checklist utilizado, bem como seus itens componentes.

Quadro 1. Itens componentes do checklist utilizado

\begin{tabular}{|c|c|}
\hline \multirow{10}{*}{$\begin{array}{l}\text { Ações para redução do } \\
\text { impacto da obra no } \\
\text { entorno }\end{array}$} & 1. Controle de poluentes da obra \\
\hline & 2. Bocas de lobo: conservadas e protegidas \\
\hline & 3. Proteção da base dos tapumes \\
\hline & 4. Implantação e operação de lava rodas \\
\hline & 5. Implantação e operação de lava bicas \\
\hline & 6. Máquinas de campo protegidas \\
\hline & 7. Descarte de águas: canaletas e caixas de decantação conservadas \\
\hline & 8. Contaminação do solo \\
\hline & 9. Estabilidade das vias \\
\hline & 10. Estratégias para controle de geração de poeira \\
\hline
\end{tabular}




\subsection{Procedimento de coleta dos dados}

No que tange a coleta dos dados, foi realizada observação direta, por meio de visitas nas obras, de forma que os pesquisadores pudessem observar a conformidade destas em relação aos itens discriminados no checklist. O preenchimento da ferramenta de pesquisa iniciou-se pelo perímetro da obra, e em seguida, foi verificada nos canteiros a disposição das baias e locais de triagem dos resíduos, bem como aspectos de segurança de equipamentos, pontos de contaminação de solo e presença de lava rodas e lava bicas em operação.

\subsection{Delimitação do universo em estudo}

Como critério de escolha das obras todas deveriam estar em etapa de produção semelhante bem como apresentar os mesmos padrões, processos construtivos e finalidades de utilização. Assim, o objeto de estudo desta pesquisa consistiu em nove obras de edifícios residenciais de alto padrão localizadas na cidade de São Paulo (SP), nos bairros do Itaim Bibi, Jardim Anália Franco, Jardim das Perdizes, Jardim Paraíso, Jardim Paulista, Santana e Vila Pirituba. A Tabela 1 apresenta as características das obras prospectadas.

Tabela 1. Característica das obras estudadas e sistemas de certificação utilizados

\begin{tabular}{|c|c|c|c|c|c|c|c|c|c|}
\hline Obra & 1 & 2 & 3 & 4 & 5 & 6 & 7 & 8 & 9 \\
\hline $\begin{array}{l}\text { Característica } \\
\text { da obra }\end{array}$ & \multicolumn{9}{|c|}{ Residencial de alto padrão } \\
\hline Fase construtiva & \multicolumn{9}{|c|}{ Fechamento de estrutura com alvenaria externa/interna e início de acabamento } \\
\hline Bairro & $\begin{array}{l}\text { Itaim } \\
\text { Bibi }\end{array}$ & $\begin{array}{l}\text { Itaim } \\
\text { Bibi }\end{array}$ & $\begin{array}{l}\text { Jardim } \\
\text { das } \\
\text { Perdizes }\end{array}$ & $\begin{array}{l}\text { Jardim } \\
\text { Paraíso }\end{array}$ & Jardim & $\begin{array}{l}\text { Itaim } \\
\text { Bibi }\end{array}$ & $\begin{array}{l}\text { Itaim } \\
\text { Bibi }\end{array}$ & $\begin{array}{l}\text { Jardim } \\
\text { das } \\
\text { Perdizes }\end{array}$ & $\begin{array}{l}\text { Jardim } \\
\text { Paraíso }\end{array}$ \\
\hline $\begin{array}{l}\text { Quantidade de } \\
\text { torres }\end{array}$ & 3 & 1 & 1 & 1 & 1 & 1 & 1 & 1 & 1 \\
\hline $\begin{array}{l}\text { Área do terreno } \\
\left(\mathrm{m}^{2}\right)\end{array}$ & 8.263 & 9.832 & 20.855 & 2.805 & 3.930 & 7.600 & 25.000 & 9.150 & 2.786 \\
\hline $\begin{array}{l}\text { Área privativa } \\
\left(\mathrm{m}^{2}\right)\end{array}$ & $\begin{array}{l}388^{(1)} \\
313^{(2)} \\
478^{(3)}\end{array}$ & 273,1 & 57 a 83 & 115 & $\begin{array}{c}110 \mathrm{a} \\
181\end{array}$ & 682 & $\begin{array}{c}230 \mathrm{a} \\
252\end{array}$ & 110 a 231 & 65 a 185 \\
\hline $\begin{array}{l}\text { Quantidade de } \\
\text { pavimentos }\end{array}$ & $\begin{array}{l}20^{(1,2)} \\
18\left(^{3}\right)\end{array}$ & 18 & 28 & 17 & 19 & 21 & 24 & 23 & 20 \\
\hline LEED & & & & & & & $x$ & & \\
\hline AQUA & & & $x$ & & & & & & \\
\hline $\begin{array}{l}\text { Consultoria } \\
\text { ambiental }\end{array}$ & & & $x$ & $x$ & $x$ & $x$ & $x$ & & \\
\hline $\begin{array}{l}\text { ISSO } 9001 \\
\text { PBQP-H }\end{array}$ & $x$ & $x$ & $x$ & $x$ & $x$ & $x$ & $x$ & $x$ & $x$ \\
\hline
\end{tabular}

${ }^{(1)}$ Torre A, ${ }^{(2)}$ Torre B, $^{(3)}$ Torre C.

Fonte: Dados da Pesquisa.

Em relação à etapa do processo executivo, todas as obras encontravam-se na fase de término de fechamento das alvenarias e início de acabamento. A seguir são apresentadas fotografias dos locais em estudo. 


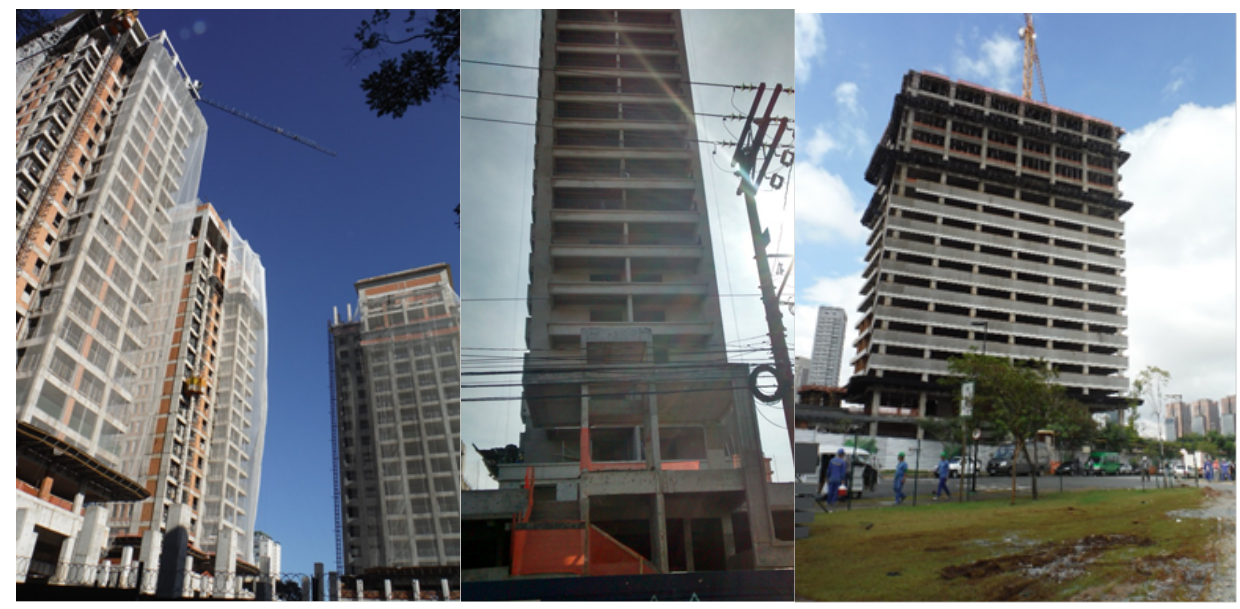

Figura 1. Canteiros das obras 1, 2 e 3 respectivamente. Fonte: Dados da Pesquisa

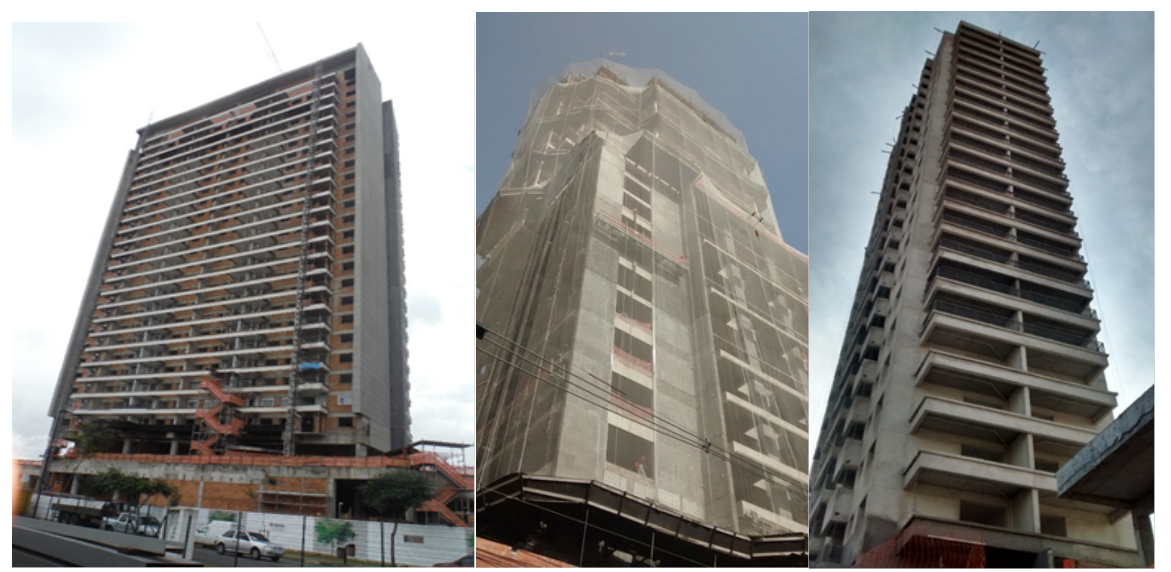

Figura 2. Canteiros das obras 4, 5 e 6 respectivamente. Fonte: Dados da Pesquisa

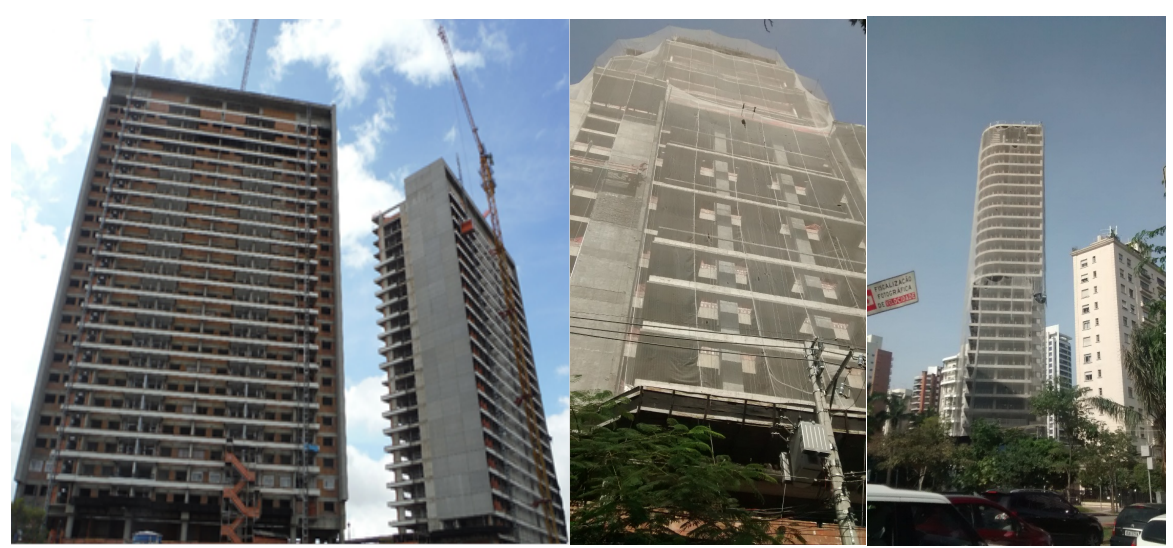

Figura 3. Canteiros das obras 7, 8 e 9 respectivamente. Fonte: Dados da Pesquisa

\section{RESULTADOS E DISCUSSÕES}

Após a coleta dos dados, pôde-se constatar que nenhuma das construtoras declarou possuir departamento específico que tratasse de assuntos e práticas ligadas à sustentabilidade em suas obras e projetos. Apenas cinco declararam ter contratado serviços de consultoria ambiental, específica para as obras em execução, o que equivale a, aproximadamente, $56 \%$ da amostra. 
Em relação aos sistemas de gestão de qualidade empregados, todas empresas declararam possuir certificações ISO 9.001 e PBQP-H nível A- SiAC/2012 (Programa Brasileiro da Qualidade e Produtividade no Habitat). Para Depexe e Paladini (2008), a certificação PBQP-H pode ser destacada, por trazer às empresas construtoras: benefícios operacionais (maior organização nas obras, redução do desperdício e aumento de produtividade); benefícios financeiros/administrativos (redução de custos, aumento de lucros, incremento de competitividade e melhoria no gerenciamento da empresa); benefícios aos clientes (aumento do nível de satisfação, melhoria da imagem da empresa, redução do número de reclamações e assistência técnica em reparos); e benefícios relacionados aos funcionários (redução de rotatividade e absenteísmo, melhoria na qualidade de trabalho e segurança, aumento da qualificação dos colaboradores).

No entanto, apesar de todas as construtoras terem declarado possuir certificações ISO 9.001 ou PBQP-H nível A- SiAC/2012, somente duas afirmaram executar suas obras com base nos critérios necessários para obtenção de selos verdes, LEED e Processo AQUA. Nenhuma construtora declarou seguir orientações para obtenção do Selo Casa Azul da Caixa Econômica Federal (SACEF). Situação semelhante já foi constatada por Afonso, Ribeiro, Souza e Cunha (2014), os quais, após estudarem obras de diversas construtoras localizadas na cidade de Uberlândia (MG), observaram que todas possuíam certificações ISO 9.001 ou PBQP-H; contudo, nenhuma possuía certificação ambiental específica para a Construção Civil, tais como LEED, AQUA ou Selo Casa Azul da CEF. Na visão dos autores, tanto a ISO 9.001 quanto o PBQP-H, são de grande importância para garantir a qualidade das construções; no entanto, estas não possuem exigências muito específicas em relação aos aspectos ambientais.

Foram levantados dados referentes às práticas realizadas nas obras com o objetivo de reduzir o impacto destas às áreas adjacentes. A Figura 4 apresenta a frequência das ações tomadas pelas obras. O Quadro 2 apresenta as estratégias utilizadas em cada uma das obras em relação as ações apresentadas na Figura 4.

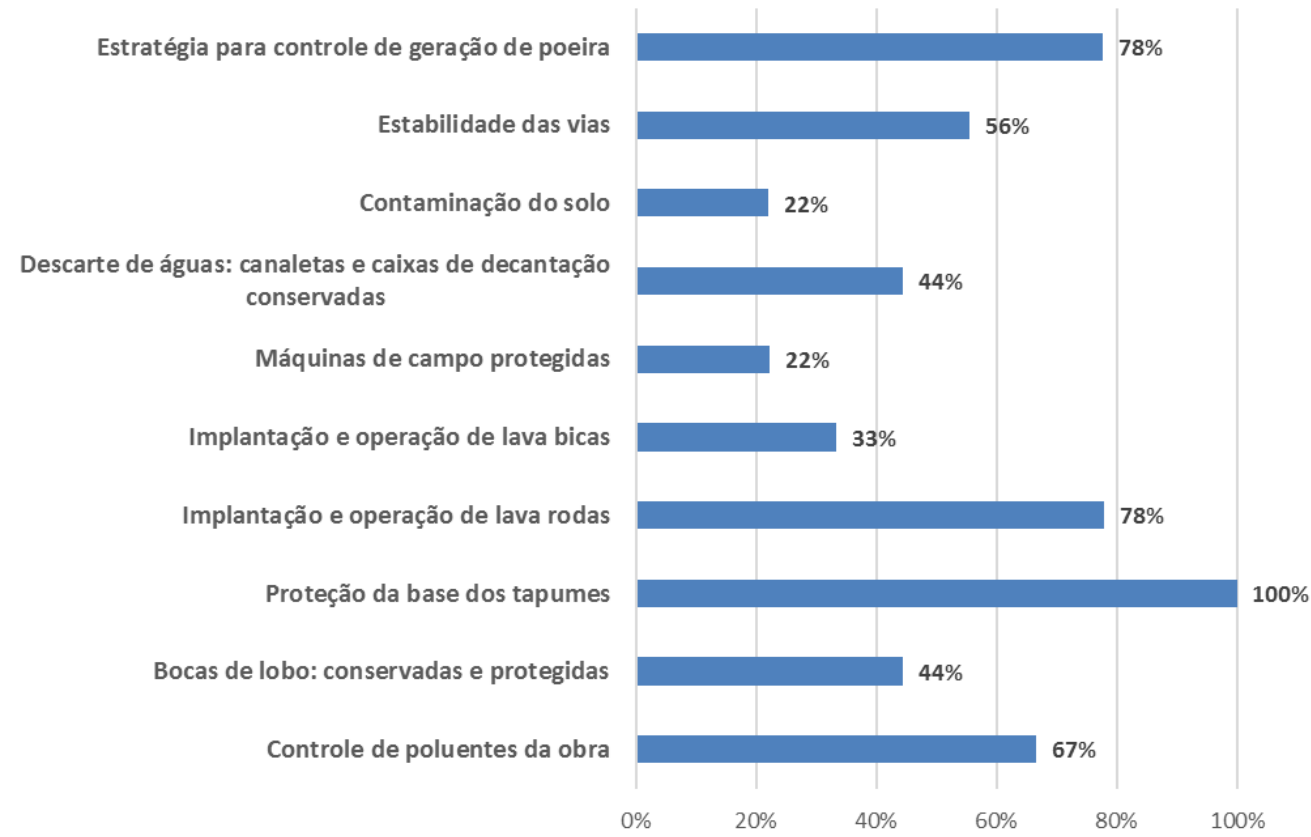

Figura 4. Frequência de ocorrência de conformidades (\%) 


\section{Fonte: Dados da Pesquisa}

De acordo com a Figura 4, nota-se que, das dez ações indicadas, cinco demonstraram frequências de conformidade abaixo de $50 \%$, e apenas uma apresentou $100 \%$. Assim, nota-se que as obras investigadas, apesar de cerca de $56 \%$ terem declarado contar com consultoria ambiental externa e todas possuírem certificação ISO 9.001 e PBQP-H, apresentam não conformidades em ações como: conservação e proteção de bocas de lobo, utilização de lavabicas e lava-rodas, conservação de canaletas e caixas de decantação, proteção de equipamentos de campo a intempéries e adoção de procedimentos de prevenção para contaminação do solo. O Quadro 2 apresenta as ações observadas em cada uma das obras e as estratégias utilizadas.

Quadro 2. Relação das estratégias utilizadas em relação as ações levantadas no "check list"

\begin{tabular}{|c|c|c|c|c|c|c|c|c|c|}
\hline Obra & 1 & 2 & 3 & 4 & 5 & 6 & 7 & 8 & 9 \\
\hline Ação & \multicolumn{9}{|c|}{ Estratégia } \\
\hline $\begin{array}{l}\text { Controle de } \\
\text { poeira }\end{array}$ & NC & NC & $\begin{array}{l}\text { Aspersão } \\
\text { com } \\
\text { caminhão } \\
\text { pipa; } \\
\text { cuidados } \\
\text { na } \\
\text { aplicação } \\
\text { de } \\
\text { argamassa, } \\
\text { utilização } \\
\text { de } \\
\text { dispositivos } \\
\text { de coleta } \\
\text { de pó. }\end{array}$ & $\begin{array}{l}\text { Aspersão } \\
\text { com } \\
\text { caminhão } \\
\text { pipa, } \\
\text { utilização } \\
\text { de } \\
\text { dispositivos } \\
\text { de coleta } \\
\text { de poeira, } \\
\text { proteção de } \\
\text { máquinas, } \\
\text { limpeza de } \\
\text { áreas. }\end{array}$ & $\begin{array}{l}\text { Aspersão } \\
\text { com } \\
\text { caminhão } \\
\text { pipa; } \\
\text { Utilização } \\
\text { de } \\
\text { dispositivos } \\
\text { de coleta } \\
\text { de pó e } \\
\text { serragem, } \\
\text { limpeza } \\
\text { constante. }\end{array}$ & $\begin{array}{l}\text { Aspersão } \\
\text { com } \\
\text { caminhão } \\
\text { pipa, } \\
\text { utilização } \\
\text { de } \\
\text { dispositivos } \\
\text { de coleta } \\
\text { de poeira, } \\
\text { cobertura } \\
\text { de baias de } \\
\text { resíduos de } \\
\text { construção } \\
\text { com } \\
\text { manta. }\end{array}$ & $\begin{array}{l}\text { Aspersão com } \\
\text { caminhão } \\
\text { pipa, } \\
\text { utilização de } \\
\text { dispositivos } \\
\text { de coleta de } \\
\text { poeira, } \\
\text { melhoria na } \\
\text { aplicação de } \\
\text { argamassa, } \\
\text { baias } \\
\text { cobertas, } \\
\text { produtos } \\
\text { devidamente } \\
\text { armazenados }\end{array}$ & $\begin{array}{l}\text { Aspersão } \\
\text { com } \\
\text { caminhão } \\
\text { pipa, } \\
\text { utilização } \\
\text { de } \\
\text { dispositivos } \\
\text { de coleta } \\
\text { de poeira, } \\
\text { proteção } \\
\text { de } \\
\text { máquinas, } \\
\text { limpeza de } \\
\text { áreas }\end{array}$ & $\begin{array}{l}\text { Aspersão } \\
\text { com } \\
\text { caminhão } \\
\text { pipa, de } \\
\text { dispositiv } \\
\text { os de } \\
\text { coleta de } \\
\text { poeira, } \\
\text { cobertura } \\
\text { de baias } \\
\text { de } \\
\text { resíduos } \\
\text { de } \\
\text { construçã } \\
\text { o com } \\
\text { manta }\end{array}$ \\
\hline $\begin{array}{l}\text { Estabilida- } \\
\text { de das vias }\end{array}$ & NC & NC & $\begin{array}{l}\text { Utilização } \\
\text { de rachão }\end{array}$ & NC & NC & $\begin{array}{l}\text { Compacta- } \\
\text { ção da via }\end{array}$ & $\begin{array}{l}\text { Compactação } \\
\text { da via }\end{array}$ & $\begin{array}{l}\text { Utilização } \\
\text { de rachão }\end{array}$ & $\begin{array}{l}\text { Utilização } \\
\text { de rachão }\end{array}$ \\
\hline $\begin{array}{l}\text { Contamina- } \\
\text { ção do solo }\end{array}$ & NC & NC & $\begin{array}{l}\text { Utilização } \\
\text { de } \\
\text { bandejas } \\
\text { sob os } \\
\text { equipamen } \\
\text { tos, } \\
\text { armazena- } \\
\text { mento de } \\
\text { produtos } \\
\text { em local } \\
\text { apropriado }\end{array}$ & NC & NC & NC & $\begin{array}{l}\text { Armazena- } \\
\text { mento de } \\
\text { produtos em } \\
\text { locais } \\
\text { adequados, } \\
\text { limpeza } \\
\text { constante, } \\
\text { manutenção } \\
\text { de } \\
\text { maquinários. }\end{array}$ & NC & NC \\
\hline $\begin{array}{l}\text { Descarte } \\
\text { das águas }\end{array}$ & NC & NC & $\begin{array}{l}\text { Manuten- } \\
\text { ção e } \\
\text { limpeza de } \\
\text { caixas e } \\
\text { canaletas } \\
\text { de descarte } \\
\text { de águas } \\
\text { pluviais }\end{array}$ & NC & NC & $\begin{array}{l}\text { Manuten- } \\
\text { ção e } \\
\text { limpeza de } \\
\text { caixas e } \\
\text { canaletas } \\
\text { de descarte }\end{array}$ & $\begin{array}{l}\text { Manutenção } \\
\text { e limpeza de } \\
\text { caixas e } \\
\text { canaletas de } \\
\text { descarte }\end{array}$ & $\begin{array}{l}\text { Manuten- } \\
\text { ção e } \\
\text { limpeza de } \\
\text { caixas e } \\
\text { canaletas } \\
\text { de descarte }\end{array}$ & NC \\
\hline $\begin{array}{l}\text { Proteção } \\
\text { de } \\
\text { máquinas }\end{array}$ & NC & NC & NC & NC & NC & $\begin{array}{l}\text { Utilização } \\
\text { de } \\
\text { cobertura } \\
\text { para } \\
\text { máquinas } \\
\text { estacioná- } \\
\text { rias }\end{array}$ & $\begin{array}{l}\text { Utilização de } \\
\text { cobertura } \\
\text { para } \\
\text { máquinas } \\
\text { estacionárias, } \\
\text { utilização de } \\
\text { bandejas sob } \\
\text { as máquinas }\end{array}$ & NC & NC \\
\hline $\begin{array}{l}\text { Implanta- } \\
\text { ção de lava }\end{array}$ & NC & NC & $\begin{array}{l}\text { Lavagem de } \\
\text { bica de } \\
\text { caminhão } \\
\text { betoneira e }\end{array}$ & NC & NC & $\begin{array}{l}\text { Lavagem } \\
\text { de bica de } \\
\text { caminhão } \\
\text { betoneira e }\end{array}$ & $\begin{array}{l}\text { Lavagem de } \\
\text { bica de } \\
\text { caminhão } \\
\text { betoneira e }\end{array}$ & NC & NC \\
\hline
\end{tabular}




\begin{tabular}{|c|c|c|c|c|c|c|c|c|c|}
\hline bicas & & & $\begin{array}{l}\text { bomba } \\
\text { antes de } \\
\text { sair da } \\
\text { obra. } \\
\text { Limpeza do } \\
\text { lava bicas }\end{array}$ & & & $\begin{array}{l}\text { bomba } \\
\text { antes de } \\
\text { sair da } \\
\text { obra. } \\
\text { Limpeza do } \\
\text { lava bicas }\end{array}$ & $\begin{array}{l}\text { bomba antes } \\
\text { de sair da } \\
\text { obra. Limpeza } \\
\text { do lava bicas }\end{array}$ & & \\
\hline $\begin{array}{l}\text { Implanta- } \\
\text { ção de lava } \\
\text { rodas }\end{array}$ & NC & NC & $\begin{array}{l}\text { Lavagem de } \\
\text { rodas de } \\
\text { caminhões } \\
\text { antes de } \\
\text { deixarem a } \\
\text { obra. } \\
\text { Limpeza do } \\
\text { lava rodas }\end{array}$ & $\begin{array}{l}\text { Lavagem de } \\
\text { rodas de } \\
\text { caminhões } \\
\text { antes de } \\
\text { deixarem a } \\
\text { obra. } \\
\text { Limpeza do } \\
\text { lava rodas }\end{array}$ & $\begin{array}{l}\text { Lavagem } \\
\text { de rodas } \\
\text { de } \\
\text { caminhões } \\
\text { antes de } \\
\text { deixarem a } \\
\text { obra. } \\
\text { Limpeza do } \\
\text { lava rodas }\end{array}$ & $\begin{array}{l}\text { Lavagem } \\
\text { de rodas } \\
\text { de } \\
\text { caminhões } \\
\text { antes de } \\
\text { deixarem a } \\
\text { obra. } \\
\text { Limpeza do } \\
\text { lava rodas }\end{array}$ & $\begin{array}{l}\text { Lavagem de } \\
\text { rodas de } \\
\text { caminhões } \\
\text { antes de } \\
\text { deixarem a } \\
\text { obra. Limpeza } \\
\text { do lava rodas }\end{array}$ & $\begin{array}{l}\text { Lavagem de } \\
\text { rodas de } \\
\text { caminhões } \\
\text { antes de } \\
\text { deixarem a } \\
\text { obra. } \\
\text { Limpeza do } \\
\text { lava rodas }\end{array}$ & $\begin{array}{l}\text { Lavagem } \\
\text { de rodas } \\
\text { de } \\
\text { caminhõe } \\
\text { s antes } \\
\text { de } \\
\text { deixarem } \\
\text { a obra. } \\
\text { Limpeza } \\
\text { do lava } \\
\text { rodas }\end{array}$ \\
\hline $\begin{array}{l}\text { Proteção } \\
\text { de base de } \\
\text { tapumes }\end{array}$ & $\begin{array}{l}\text { Manuten } \\
\text {-ção } \\
\text { para } \\
\text { evitar } \\
\text { perda de } \\
\text { sedimen } \\
\text { tos para } \\
\text { a rua }\end{array}$ & $\begin{array}{l}\text { Manu- } \\
\text { tenção } \\
\text { para } \\
\text { evitar } \\
\text { perda } \\
\text { de sedi- } \\
\text { mentos } \\
\text { para a } \\
\text { rua } \\
\end{array}$ & $\begin{array}{l}\text { Manuten- } \\
\text { ção para } \\
\text { evitar } \\
\text { perda de } \\
\text { sedimentos } \\
\text { para a rua }\end{array}$ & $\begin{array}{l}\text { Manuten- } \\
\text { ção para } \\
\text { evitar perda } \\
\text { de } \\
\text { sedimentos } \\
\text { para a rua }\end{array}$ & $\begin{array}{l}\text { Manuten- } \\
\text { ção para } \\
\text { evitar } \\
\text { perda de } \\
\text { sedimentos } \\
\text { para a rua }\end{array}$ & $\begin{array}{l}\text { Manuten- } \\
\text { ção para } \\
\text { evitar } \\
\text { perda de } \\
\text { sedimentos } \\
\text { para a rua }\end{array}$ & $\begin{array}{l}\text { Manutenção } \\
\text { para evitar } \\
\text { perda de } \\
\text { sedimentos } \\
\text { para a rua }\end{array}$ & $\begin{array}{l}\text { Manuten- } \\
\text { ção para } \\
\text { evitar } \\
\text { perda de } \\
\text { sedimentos } \\
\text { para a rua }\end{array}$ & $\begin{array}{l}\text { Manuten } \\
\text { ção para } \\
\text { evitar } \\
\text { perda de } \\
\text { sedimen- } \\
\text { tos para a } \\
\text { rua }\end{array}$ \\
\hline $\begin{array}{l}\text { Bocas de } \\
\text { lobo }\end{array}$ & $\mathrm{NC}$ & $\mathrm{NC}$ & $\begin{array}{l}\text { Limpeza e } \\
\text { manuten- } \\
\text { ção }\end{array}$ & $\begin{array}{l}\text { Limpeza e } \\
\text { manuten- } \\
\text { ção }\end{array}$ & $\begin{array}{l}\text { Limpeza e } \\
\text { manuten- } \\
\text { ção }\end{array}$ & $\begin{array}{l}\text { Limpeza e } \\
\text { manuten- } \\
\text { ção }\end{array}$ & $\mathrm{NC}$ & $\mathrm{NC}$ & NC \\
\hline $\begin{array}{l}\text { Controle de } \\
\text { poluentes }\end{array}$ & NC & NC & $\begin{array}{l}\text { Gerenciam } \\
\text { ento de } \\
\text { resíduos, } \\
\text { armazena- } \\
\text { mento } \\
\text { adequado } \\
\text { de } \\
\text { produtos, } \\
\text { controle de } \\
\text { poeira, } \\
\text { manuten- } \\
\text { ção de } \\
\text { equipamen } \\
\text { tos. }\end{array}$ & $\begin{array}{l}\text { Gerencia- } \\
\text { mento de } \\
\text { resíduos } \\
\text { gerados, } \\
\text { controle de } \\
\text { emissão de } \\
\text { particulado, } \\
\text { controle de } \\
\text { ruído de } \\
\text { equipamen- } \\
\text { tos }\end{array}$ & $\begin{array}{l}\text { Gerencia- } \\
\text { mento de } \\
\text { resíduos } \\
\text { gerados, } \\
\text { controle de } \\
\text { emissão de } \\
\text { particulado } \\
\text {, controle } \\
\text { de ruído de } \\
\text { equipamen } \\
\text {-tos }\end{array}$ & $\begin{array}{l}\text { Gerencia- } \\
\text { mento de } \\
\text { resíduos } \\
\text { gerados, } \\
\text { controle de } \\
\text { emissão de } \\
\text { particulado } \\
\text {,monitora- } \\
\text { mento de } \\
\text { efluentes }\end{array}$ & $\begin{array}{l}\text { Gerenciament } \\
\text { o de resíduos, } \\
\text { armazena- } \\
\text { mento } \\
\text { correto de } \\
\text { materiais, } \\
\text { controle de } \\
\text { ruídos e } \\
\text { material } \\
\text { particulado, } \\
\text { manutenção } \\
\text { de equipa- } \\
\text { mentos, } \\
\text { monitoramen } \\
\text {-to de } \\
\text { efluentes }\end{array}$ & NC & $\begin{array}{l}\text { Gerencia } \\
\text { mento de } \\
\text { resíduos, } \\
\text { armazena } \\
\text { mento } \\
\text { correto } \\
\text { de } \\
\text { materiais, } \\
\text { controle } \\
\text { de ruídos } \\
\text { e } \\
\text { material } \\
\text { particu- } \\
\text { lado,ma- } \\
\text { nutenção } \\
\text { de } \\
\text { equipa- } \\
\text { mentos. }\end{array}$ \\
\hline
\end{tabular}

Fonte: Dados da Pesquisa

As ações apresentadas no Quadro 2 configuram-se de grande importância na redução dos impactos causados pelas obras no entorno; porém, nem todas apresentaram estratégias para tal; mesmo algumas possuindo consultoria ambiental. Observa-se que apenas o item referente a proteção da base dos tapumes foi constatado em todas as obras estudadas. Esta proteção possui por objetivo impedir, além da entrada de pessoas estranhas a obra, a saída de sedimentos para a rua tais como: solo, areia, poeira, entre outros.

Em relação a ação para se evitar contaminação do solo e proteção de máquinas a intempéries, apenas duas obras apresentaram estratégias para tal. As ações para se evitar contaminação do solo relatadas foram: utilização de bandejas metálicas abaixo de equipamentos, armazenamento de produtos em locais adequados (de forma que aqueles com potencial contaminante não ficassem diretamente em contato com o solo) e manutenção constante dos equipamentos (para que estes não apresentem vazamentos do combustível, óleo ou graxa). Deve-se destacar que a falta de preocupação com a contaminação do solo pode, em algumas 
situações, causar a contaminação do lençol freático. Este processo pode ocorrer por meio da simples percolação do contaminante pelos poros do solo, bem como pela lixiviação deste por meio de água de chuva. Deve-se destacar que a proteção de equipamentos e máquinas contra intempéries, além de aumentar a vida útil destes, também evita a contaminação do solo por meio de vazamentos de combustíveis, graxas e óleos. Araújo (2009) acrescenta que a falta de proteção e conservação de equipamentos e máquinas de campo poderá causar riscos à saúde ocupacional dos trabalhadores, bem como excessiva emissão de poluentes e ruídos.

A correta implantação e manutenção de lava bicas e lava rodas nas obras, tem por intuito proporcionar a limpeza dos caminhões (betoneiras e caçambas) e bombas de concreto ao saírem dos canteiros, de forma que estes não deixem resíduos nas vias públicas. A presença e a manutenção de elementos para descarte de águas (tais como: caixas de decantação, canaletas, bocas de lobo, etc.) de uma obra são importantes na retenção de materiais inertes e partículas carreadas pelas águas pluviais, para que, quando estas sejam lançadas no sistema de drenagem superficial urbano, não causem entupimento de bocas de lobo e bueiros. A estabilização das vias possui importância de reduzir a quantidade de poeira gerada durante o trânsito de equipamentos nas obras, bem como garantir condições de trafegabilidade aceitáveis.

Em relação ao controle de poluição, verifica-se que algumas obras relataram a adoção de estratégias de redução ruídos, indicando a preocupação destas com a poluição sonora gerada pelas atividades de construção. Também se observa a adoção de ferramentas de gerenciamento de resíduos de construção, o que é obrigatório de acordo com a resolução $n^{\circ}$ 307/2002 do Conselho Nacional do Meio Ambiente (CONAMA); além da utilização de máquinas e sistemas que emitam menores quantidades de materiais particulados e poluentes atmosféricos.

A seguir, na Figura 5 são apresentadas as frequências de ocorrência de conformidades e não conformidades para cada uma das obras estudadas.

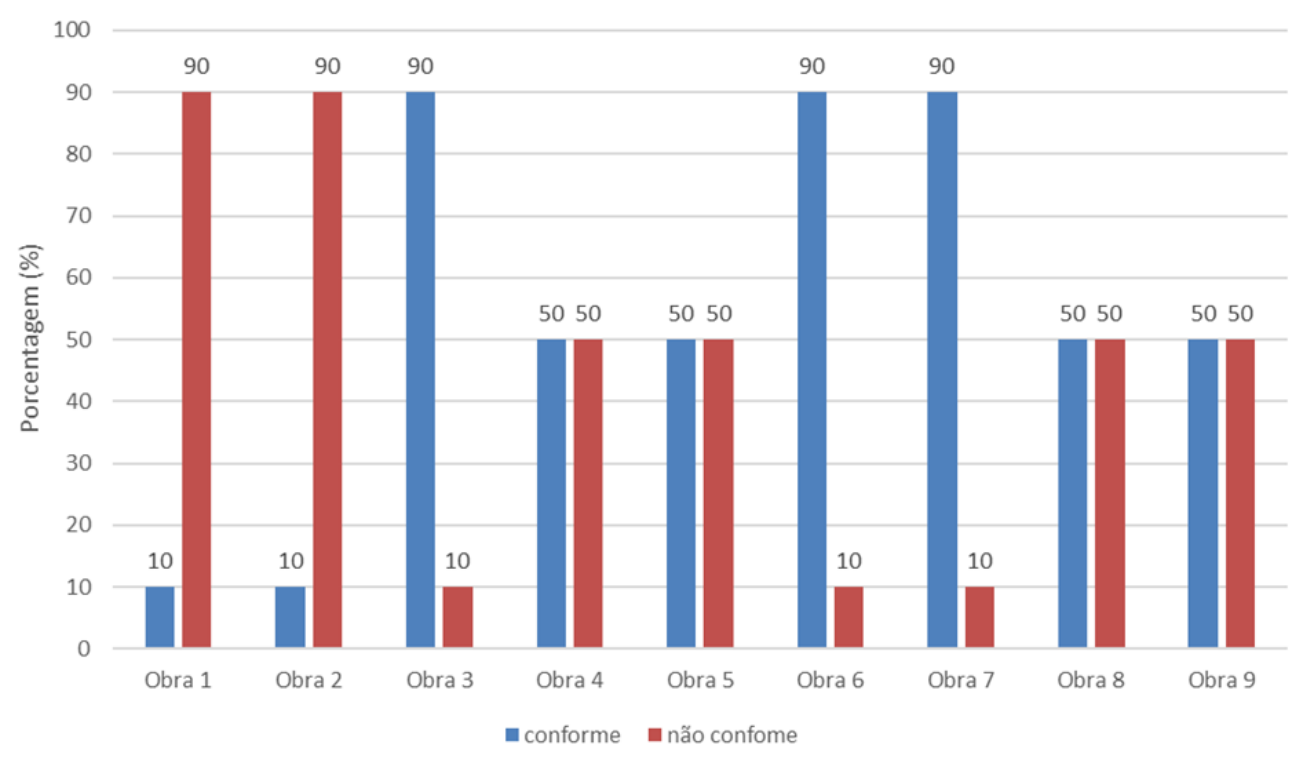

Figura 5. Relação entre frequência (\%) de ocorrência de conformidade e não conformidade das obras. Fonte: Dados da Pesquisa

Pode-se observar, por meio da Figura 5 e do Quadro 2, que as Obras 3 e 7 possuem os maiores percentuais de frequência de conformidade de adoção de práticas de redução do impacto das obras no entorno. Ressalta-se que ambas estão sendo certificadas pelo Processo 
AQUA e LEED, respectivamente. Este fato é explicado por Piccoli, Kern, Gonzalés e Hirota (2010), os quais comentam que, além da abordagem em relação ao desempenho da obra finalizada, os sistemas de certificação verde, também fazem exigências durante a etapa de produção dos edifícios, visando mitigar os impactos ambientais do canteiro de obras, tais como: poeira, geração de resíduos, consumo de energia, poluição etc. Também deve-se destacar a obra 6, a qual, apesar de não ter relatado estar passando por certificação LEED ou AQUA, apresentou frequência de conformidade equivalente a $90 \%$. Percebe-se, por meio da Figura 5, que as Obras 4 e 5, apesar de declararem contar com consultoria ambiental externa, apresentaram apenas $50 \%$ de conformidade em relação aos itens discriminados no checklist. Assim, no intuito de verificar a importância do papel da consultoria ambiental em relação à implantação de medidas de mitigação de impactos gerados pelas obras, também foi realizada uma análise bidimensional utilizando-se tabela de referência cruzada, apresentada a seguir:

Tabela 2. Análise bidimensional entre consultoria ambiental e práticas adotadas nas obras

\begin{tabular}{|c|c|c|c|c|}
\hline \multirow[t]{2}{*}{ Possui consultoria ambiental } & \multicolumn{4}{|c|}{ Controle de Poluentes da obra } \\
\hline & Conforme & Obra(s) & Não Conforme & Obra(s) \\
\hline Sim & 5 & $3,4,5,6,7$ & 0 & $\mathrm{nc}$ \\
\hline Não & 1 & 9 & 3 & $1,2,8$ \\
\hline \multirow[t]{2}{*}{ Possui consultoria ambiental } & \multicolumn{4}{|c|}{ Bocas de lobo: conservadas e protegidas } \\
\hline & Conforme & Obra(s) & Não Conforme & Obra(s) \\
\hline Sim & 4 & $3,4,5,6$ & 1 & 7 \\
\hline Não & 0 & $\mathrm{nc}$ & 4 & $1,2,8,9$ \\
\hline \multirow[t]{2}{*}{ Possui consultoria ambiental } & & \multicolumn{3}{|c|}{ Proteção da base dos tapumes } \\
\hline & Conforme & Obra(s) & Não Conforme & Obra(s) \\
\hline Sim & 5 & $3,4,5,6,7$ & 0 & $\mathrm{nc}$ \\
\hline Não & 4 & $1,2,8,9$ & 0 & $\mathrm{nc}$ \\
\hline \multirow[t]{2}{*}{ Possui consultoria ambiental } & \multicolumn{4}{|c|}{ Implantação e operação de lava rodas } \\
\hline & Conforme & Obra(s) & Não Conforme & Obra(s) \\
\hline Sim & 5 & $3,4,5,6,7$ & 0 & $\mathrm{nc}$ \\
\hline Não & 2 & 8,9 & 2 & 1,2 \\
\hline \multirow[t]{2}{*}{ Possui consultoria ambiental } & \multicolumn{4}{|c|}{ Implantação e operação de lava bicas } \\
\hline & Conforme & Obra(s) & Não Conforme & Obra(s) \\
\hline Sim & 3 & $3,6,7$ & 2 & 4,5 \\
\hline Não & 0 & nc & 4 & $1,2,8,9$ \\
\hline \multirow[t]{2}{*}{ Possui consultoria ambiental } & \multicolumn{4}{|c|}{ Máquinas de campo protegidas } \\
\hline & Conforme & Obra(s) & Não Conforme & Obra(s) \\
\hline Sim & 2 & 6,7 & 3 & $3,4,5$ \\
\hline Não & 0 & nc & 4 & $1,2,8,9$ \\
\hline \multirow[t]{2}{*}{ Possui consultoria ambiental } & \multicolumn{4}{|c|}{ Descarte de águas: canaletas e caixas de decantação conservadas } \\
\hline & Conforme & Obra(s) & Não Conforme & Obra(s) \\
\hline Sim & 3 & $3,6,7$ & 2 & 4,5 \\
\hline Não & 1 & 8 & 4 & $1,2,9$ \\
\hline \multirow[t]{2}{*}{ Possui consultoria ambiental } & \multicolumn{4}{|c|}{ Contaminação do solo } \\
\hline & Conforme & Obra(s) & Não Conforme & Obra(s) \\
\hline Sim & 2 & 3,7 & 3 & $4,5,6$ \\
\hline Não & 0 & $\mathrm{nc}$ & 4 & $1,2,8,9$ \\
\hline \multirow[t]{2}{*}{ Possui consultoria ambiental } & \multicolumn{4}{|c|}{ Estabilidade das vias (aspersão de água, concretagem, brita) } \\
\hline & Conforme & Obra(s) & Não Conforme & Obra(s) \\
\hline Sim & 3 & $3,6,7$ & 2 & 4,5 \\
\hline Não & 2 & 8,9 & 2 & 1,2 \\
\hline \multirow[t]{2}{*}{ Possui consultoria ambiental } & \multicolumn{4}{|c|}{ Estratégia para controle de geração de poeira } \\
\hline & Conforme & Obra(s) & Não Conforme & Obra(s) \\
\hline
\end{tabular}




\begin{tabular}{r|c|c|c|c}
\hline Sim & 5 & $3,4,5,6,7$ & 0 & $\mathrm{nc}$ \\
\hline Não & 2 & 8,9 & 2 & 1,2 \\
\hline
\end{tabular}

Fonte: Dados da Pesquisa.

Verifica-se por meio da Tabela 2 que as obras que possuem consultoria ambiental externa adotam, em comum, práticas de controle de poluentes da obra, proteção de base de tapumes, conservação e proteção de bocas de lobo, implantação de lava rodas e estratégias para controle de poeira gerada na obra. Entretanto, algumas ações de mitigação apresentadas no checklist, tais como: implantação de lava bicas, proteção das máquinas de campo contra intempéries, manutenção de caixas de decantação de água, preocupação com contaminação do solo e estratégias para estabilização das vias, são observadas apenas em algumas destas obras. Tal situação chama atenção para a efetividade das consultorias ambientais realizadas, uma vez que cabe a estas, não apenas a determinação da implantação das ações necessárias de mitigação de impacto das obras no entorno; mas, também fiscalizar a eficiência de operação destas, fato este que não se constatou por meio dos dados apresentados na Tabela 2.

\section{CONCLUSÕES}

A Construção Civil consiste em uma das atividades industriais que mais causa impactos ao meio ambiente, quer seja por meio da extração de matéria-prima necessária ao seu consumo, geração de resíduos ou imposição de impactos nas regiões de entorno das obras, tais como: poluição do ar e sonora, poeira, contaminação de solo, sujeira de logradouros, entupimento de sistemas de drenagem de água pluvial etc. Dessa forma, é de suma importância que as empresas de construção prevejam e executem, em seus canteiros de obras, ferramentas, metodologias e procedimentos que evitem, ou ao menos reduzam, a ocorrência destes impactos na vizinhança.

Dentre deste contexto, este trabalho levantou as práticas de mitigação dos impactos causados por nove obras, em suas regiões de entorno. As construções pesquisadas foram do tipo residencial de alto padrão, localizadas em diferentes regiões da cidade de São Paulo. A ferramenta utilizada para coleta dos dados consistiu em um "check list" cujos itens foram baseados nas principais diretrizes ambientais de programas de certificação verde.

De acordo com os resultados obtidos e análises efetuadas, pode-se concluir que diversas obras de construção estudadas demonstraram possuir deficiências na adoção de ferramentas de redução do impacto de suas obras na vizinhança, mesmo algumas tendo declarado possuírem acompanhamento de consultoria ambiental externa. As empresas que declararam adotar a maior dos procedimentos listados nos checklists, estão passando por processo de certificação verde (LEED e Processo AQUA), com exceção da Obra 6.

Todas as obras estudadas declararam possuir sistemas de gestão de qualidade ISO 9.001/2008 ou PBQP-H nível A (SiAC/2012). No entanto, tal fato não demonstrou relação direta com a observância de algumas obras em relação à conformidade com os procedimentos relacionados no checklist. De acordo com Afonso, Ribeiro, Souza e Cunha (2014), tanto a ISO 9.001 quanto o PBQP-H, são de grande importância para garantir a qualidade das construções; porém, estas não possuem exigências muito específicas em relação aos aspectos ambientais.

Para futuros trabalhos, sugere-se que outras obras e empresas de Construção Civil sejam pesquisadas, tanto na cidade de São Paulo, quanto em outras cidades e Estados, bem como sejam desenvolvidas pesquisas quantitativas (surveys) com construtoras-membros de 
associações ou sindicatos relacionados à Construção Civil, para verificar o quanto dessas práticas estão sendo implementadas nas referidas empresas. Este trabalho contribui para o meio acadêmico, bem como para a sociedade, de forma geral, por trazer à tona a importância da redução dos impactos ambientais nas regiões urbanas das cidades

\section{REFERÊNCIAS}

Achillas, C; Banias, S, G.; Moussiopoulos, N.; Papaioannou, I.; Vlachokostas, C. (2011) A webbased Decision Support System for the optimal management of construction and demolition waste. Waste Management, v. 31, n. 12, p. 2497-2502.

Afonso, P.P.; Ribeiro, F.A.B.S.; Souza, L.H.F.; Cunha, D.A.I. (2014) Sustentabilidade ambiental no setor da construção civil: comparação das medidas adotadas por construtoras do município de Uberlândia/MG. Anais... in: V Congresso Brasileiro de Gestão Ambiental, IBEAS - Instituto Brasileiro de Estudos Ambientais.

Alcino, P. Análise de Métodos de Avaliação de Sustentabilidade do Ambiente Construído: O Caso dos Conjuntos Habitacionais. (2008). Dissertação (Mestrado em Engenharia Civil), Escola Politécnica da Universidade de São Paulo. São Paulo.

Alexandre. N. M. C.; Coluci, M. Z. O. (2011) Validade de conteúdo nos processos de construção e adaptação de instrumentos de medidas. Ciências \& Saúde Coletiva, Rio de Janeiro, v. 16, n. 7, p. 3061-3068.

Araújo, V.M. Práticas recomendadas para a gestão mais sustentável de canteiro de obras. Dissertação (Mestrado em Engenharia). 2009. 229 p. Escola Politécnica, Universidade de São Paulo, São Paulo, 2009.

Arif, M.; Bendi, B.; Toma-Sabbagh, T. (2012) Construction waste management in India: an exploratory study. Construction innovation, v.12, n.2, p.133-155.

Associação Brasileira de Normas Técnica. ABNT NBR 10.004: Resíduos Sólidos - Classificação. Rio de Janeiro, 1987.

Bomfati, E.; Silva, M. C. (2004). Os impactos sociais e ambientais do crescimento econômico no território urbano: interesses locais entre agentes do setor privado na cidade de Ponta Grossa - PR. Revista Educação \& Tecnologia. Curitiba, Editora do CEFET-PR, v.8, p. 185 - 208.

Casado, M. Green Buildings, antes tarde do que nunca. IETEC - Instituto de Educação Tecnológica. Belo Horizonte. Fev. 2012. Disponível em: <http://www.techoje.com.br/site/techoje/categoria/detalhe_artigo/595> Acesso em: 06 set. 2016.

Coelho, L. Certificação Ambiental. Revista Techne, V. 155. 2010. Disponível em: <http://www.revistatechne.com.br/engenharia-civil/155/carimbo-verde-162886-1.asp> Acesso em 24 de maio 2012.

Conselho Nacional do Meio Ambiente - CONAMA. Resolução 307 de 5 de julho de 2002. Brasil, pp 7. 
Depexe, M.D.; Paladini, E.P. (2008) Benefícios da implementação e certificação de sistemas de gestão da qualidade em empresas construtoras. Revista Gestão Industrial, v. 4, n. 2, p145161.

Elkington, J. (1997) Cannibals with forks: the triple bottom line of twenty first century business. Ed.Capstone, Mankato, MN.

Fundação Vanzolini. Edifícios habitacionais - Processo AQUA. Referencial técnico de certificação, 2010.

Godoy, A.S. (1995) Pesquisa qualitativa: tipos fundamentais. Revista de Administração de Empresas - RAE. São Paulo, v.35, n.3, p 20-29.

Grunberg, P.R.M.; Medeiros, M.H.F.; Tavares, S.F. (2014) Certificação ambiental de edificações: comparação entre Leed for homes, Processo ACQUA e Selo Casa Azul. Revista Ambiente e Sociedade. Campinas/SP, v.17, n.2, pp. 195-214.

Lima, R. S. (2009). Guia para elaboração de projeto de gerenciamento de resíduos da construção civil. Série de Publicações Temáticas do Crea-PR. Curitiba: Crea.

Linhares, S.P.; Ferreira, J.A.; Ritter, E. (2007) Avaliação da implantação da Resolução n.307/2002 do CONAMA sobre gerenciamento dos resíduos de construção civil. Estudos Tecnológicos em Engenharia, v.3, n.3, pp.176-194.

Miguel, P.A.C. (2007) Estudo de caso na engenharia de produção: estruturação e recomendação para sua condução. Revista Produção, v.17, n.1, p.216-229.

Morais, G.M.D. Diagnóstico da deposição clandestina de resíduos de construção e demolição em bairros periféricos de Uberlândia: Subsídios para uma gestão sustentável. 2006. 220p Dissertação (Mestrado em Engenharia Civil). Faculdade de Engenharia Civil. Universidade Federal de Uberlândia. Uberlândia/MG, 2006.

Motta, S R. F. Sustentabilidade na Construção Civil: Crítica, síntese, modelo de política e gestão de empreendimentos. Dissertação (Mestrado em Engenharia Civil). Programa de Pós-graduação em Construção Civil, UFMG. Belo Horizonte, 2009.

Oliveira, M J. E. (2002). Materiais descartados pelas obras de construção civil: Estudo dos resíduos de concreto para reciclagem. 2002. 191p. Tese (Doutorado em Geociências e Meio Ambiente). Instituto de Geociências e Ciências Exatas da Universidade Estadual Paulista, UNESP. Rio Claro, 2002.

Paschoalin Filho, J, A; Graudenz, G, S. (2012) Destinação irregular de resíduos de construção e demolição (RCD) e seus impactos na saúde coletiva. Revista de Gestão Social e Ambiental, v.6, n.1, p. 127-142.

Paschoalin Filho, J. A.; Dias, A. J. D.; Cortes, P. L.: Duarte E. B. L. (2013). Manejo de resíduos de demolição gerados durante as obras da arena de futebol Palestra Itália (Allianz Parque) localizada na cidade de São Paulo/Brasil. Revista Holos, v.6, n.3, p.73-91. 
Paschoalin Filho, J. A.; Storopoli, J. H.; Dias, A. J. G.; Duarte, E. B. L. (2015) Gerenciamento dos resíduos de demolição gerados nas obras de um edifício localizado na Zona Leste da Cidade de São Paulo/SP. Desenvolvimento em Questão, v. 13, n. 30, p. 265-305.

Piccoli, R.; Kern, A.P.; Gonzalez, M.A.; Hirota, E.H. (2010) A certificação ambiental de desempenho ambiental de prédios: exigências usuais e novas atividades na gestão da construção. Revista Ambiente Construído, Porto Alegre, v.10, n.3, p.69-79.

Yin, R. (2010). Estudo de caso: planejamento e métodos. 4ạ Edição, Porto Alegre: Bookman. 